\title{
Expression of biofilm-associated genes of Streptococcus mutans in response to glucose and sucrose
}

\author{
Moshe Shemesh, Avshalom Tam and Doron Steinberg \\ Institute of Dental Sciences, Faculty of Dental Medicine, Hebrew University-Hadassah, POB 12272 \\ Jerusalem 91120, Israel
}

Correspondence

Doron Steinberg

dorons@cc.huji.ac.il

\begin{abstract}
Streptococcus mutans is known as a primary pathogen of dental caries, one of the most common human infectious diseases. Exopolysaccharide synthesis, adherence to tooth surface and biofilm formation are important physiological and virulence factors of $S$. mutans. In vitro comparative gene expression analysis was carried out to differentiate 10 selected genes known to be mostly involved in $S$. mutans biofilm formation by comparing the expression under biofilm and planktonic environments. Real-time RT-PCR analyses indicated that all of the genes tested were upregulated in the biofilm compared to cells grown in planktonic conditions. The influence of simple dietary carbohydrates on gene expression in S. mutans biofilm was tested also. Among the tested genes, in the biofilm phase, the greatest induction was observed for $g t f$ and $f t f$, which are genes encoding the extracellular polysaccharide-producing enzymes. Biofilm formation was accompanied by a 22fold induction in the abundance of mRNA encoding glucosyltransferase B (GTFB) and a 14.8 fold increase in mRNA encoding GTFC. Levels of mRNA encoding fructosyltransferase were induced approximately 11.8-fold in biofilm-derived cells. Another notable finding of this study suggests that glucose affects the expression of $S$. mutans GS5 biofilm genes. In spite of a significant upregulation in biofilm-associated gene expression in the presence of sucrose, the presence of glucose with sucrose reduced expression of most tested genes. Differential analysis of the transcripts from $S$. mutans, grown in media with various nutrient contents, revealed significant shifts in the expression of the genes involved in biofilm formation. The results presented here provide new insights at the molecular level regarding gene expression in this bacterium when grown under biofilm conditions, allowing a better understanding of the mechanism of biofilm formation by $S$. mutans.
\end{abstract}

Received 2 January 2007 Accepted 29 June 2007

\section{INTRODUCTION}

Streptococcus mutans is a bacterium that has evolved to depend on a biofilm lifestyle for survival and persistence in its natural ecosystem. S. mutans is assembled as communities attached to dental surfaces and forms matrix-embedded biofilms (Marsh, 2005). Such biological organization provides a sheltered microenvironment for the immobilized bacteria (Bowden \& Hamilton, 1998; Hall-Stoodley et al., 2004). Adhesion is the initial step in the formation of biofilm communities. As a primary bacterial agent of dental caries, the mechanisms by which $S$. mutans adheres to tooth surfaces are important potential targets for anti-cariogenic intervention. Sucrose-dependent mechanisms of adherence, as mediated by extracellular

Abbreviations: CLSM, confocal laser scanning microscope; $\mathrm{C}_{t}$, threshold cycle; FTF, fructosyltransferase; GBP, glucan-binding protein; GTF, glucosyltransferase.

A figure showing depth analysis of live/dead stained biofilms is available as supplementary material with the online version of this paper. enzymes [glucosyltransferases (GTFs) and fructosyltransferases (FTFs)] and glucan-binding proteins (GBPs), have well-established roles in the virulence of $S$. mutans (Kuramitsu, 1993, 2001; Steinberg, 2000; Banas \& Vickerman, 2003). Sucrose-independent mechanisms can also foster microbial colonization by providing binding sites for bacteria (Lee et al., 1989; Shemesh \& Steinberg, 2006).

Beyond initial adherence, it appears that a variety of genes are required for the adaptation of $S$. mutans and other oral streptococci in biofilms. Cells existing in the biofilm have phenotypic characteristics, which are distinct from those of their planktonic counterparts, probably accompanied with significant changes in the patterns of gene expression (Costerton, 1987; Whiteley et al., 2001). These include genes associated with intercellular communication systems and environmental sensing systems, regulators of carbohydrate metabolism, and adhesion-promoting genes (Lemos \& Burne, 2002; Shemesh et al., 2007; Senadheera et al., 2005). Among the genes selected for the study were $b r p A$ 
(lytR), comDE and $v i c R$ encoding regulatory proteins (Li et al., 2002; Chatfield et al., 2005; Senadheera et al., 2005; Wen \& Burne, 2002), the adhesion-promoting genes $g b p B$ and spaP (Banas \& Vickerman, 2003; Jakubovics et al., 2005), and also the genes encoding polysaccharide synthesizing enzymes, including $g t f B C$ and $f t f$ (Shemesh et al., 2006; Steinberg, 2000). Moreover, it was of interest to assess the expression of genes, such as relA, which is required by $S$. mutans to form stable biofilms and tolerate acid stress (Lemos et al., 2004), and smu630, which is important in both sucrose-dependent and sucrose-independent biofilm formation (Brown et al., 2005).

A number of studies have indicated that expression of the genes responsible for biofilm formation is dependent on environmental conditions (Kiska \& Macrina, 1994; Hudson \& Curtiss, 1990; Li \& Burne, 2001), and is also genetically regulated (Kiska \& Macrina, 1994; Lee et al., 2004). It was therefore of interest to identify transcriptional changes for several genes that accompany the formation of an in vitro biofilm by the most important pathogens in the development of dental caries, such as $S$. mutans. To assess the expression of genes known to be involved in biofilm formation by $S$. mutans, for comparison with the expression of genes in planktonic cells, real-time PCR was used. Because of the pivotal role of the dietary carbohydrates in the pathogenicity of S. mutans biofilm, the influence of such carbohydrates on gene expression, as well as on biofilm thickness, was tested also.

\section{METHODS}

Bacterial strains and culture conditions. S. mutans GS5, a clinical isolate commonly used in dental research (Yoshida \& Kuramitsu, 2002), was grown overnight in either brain heart infusion (BHI) broth (Difco Laboratories) or TY medium (1.4\% tryptone, $0.8 \%$ yeast extract) at $37{ }^{\circ} \mathrm{C}$ in air atmosphere supplemented with $5 \% \mathrm{CO}_{2}$ (v/v). Cultures of $S$. mutans were diluted $1: 50$, inoculated into fresh (BHI or TY) media and grown in polystyrene test tubes for an additional $24 \mathrm{~h}\left[37{ }^{\circ} \mathrm{C}\right.$, air atmosphere supplemented with $\left.5 \% \mathrm{CO}_{2}(\mathrm{v} / \mathrm{v})\right]$. For biofilm generation, $20 \mu \mathrm{l} \mathrm{S}$. mutans culture, grown as described above, was seeded in $20 \mathrm{~mm}$ diameter, $15 \mathrm{~mm}$ deep sterile polystyrene multidishes and cultivated with $1 \mathrm{ml}$ (BHI or TY) medium at $37{ }^{\circ} \mathrm{C}$ in air atmosphere supplemented with $5 \% \mathrm{CO}_{2}(\mathrm{v} / \mathrm{v})$. After $24 \mathrm{~h}$, the biofilm generated in BHI or TY media (final $\mathrm{pH} 5.1 \pm 0.3$ ) was washed with $1 \mathrm{ml}$ ice-cold $9 \mathrm{~g} \mathrm{NaCl}^{-1}$.

To analyse the effect of simple sugars on the gene expression in $S$. mutans biofilm, the availability of carbohydrate sources was prearranged as follows: (i) unsupplemented TY medium, (ii) TY medium supplemented with $10 \mathrm{~g}$ sucrose $\mathrm{l}^{-1}$ (Frutarom), (iii) TY medium supplemented with $40 \mathrm{~g}$ sucrose $1^{-1}$, (iv) TY medium supplemented with $2 \mathrm{~g}$ glucose $1^{-1}$ (Frutarom), (v) TY medium supplemented with $10 \mathrm{~g}$ sucrose $1^{-1}$ and $2 \mathrm{~g}$ glucose $\mathrm{l}^{-1}$, (vi) TY medium supplemented with $40 \mathrm{~g}$ sucrose $1^{-1}$ and $2 \mathrm{~g}$ glucose $1^{-1}$, (vii) unsupplemented BHI medium, (viii) BHI medium supplemented with $10 \mathrm{~g}$ sucrose $1^{-1}$ and (ix) BHI medium supplemented with $40 \mathrm{~g}$ sucrose $1^{-1}$.

Confocal laser scanning microscopy (CLSM). The biofilms constructed on polystyrene multidishes were stained with LIVE/ DEAD BacLight fluorescent dye (Molecular Probes) (1:100) for
10 min. Fluorescence emission of the PBS-washed samples was measured using a Zeiss LSM 510 CLSM (Carl Zeiss Microscopy). In each experiment, exciting laser intensity, background level, contrast and electronic zoom size were maintained at the same level. At least three random fields were analysed in each experiment. A series of optical cross-section images were acquired at $5 \mu \mathrm{m}$ depth intervals from the surface, through the vertical axis of the specimen, using a computer-controlled motor drive. Three dimensional confocal images were reconstituted and processed for display using Adobe Photoshop version 7.0 software.

RNA extraction. Extraction of the total RNA was performed as described previously (Tam et al., 2006) with slight modification. Biofilm-grown S. mutans cells were suspended in TRI reagent (SigmaAldrich) and dislodged by scraping into a $2 \mathrm{ml}$ microcentrifuge tube containing $0.4 \mathrm{ml} 1 \mathrm{~mm}$ diameter glass beads (Sigma-Aldrich). The cells were disrupted with the aid of a FastPrep cell disrupter (Bio 101; Savant Instruments), centrifuged and the RNA containing supernatant was supplemented with 1-bromo-3-chloropropane (Molecular Research Center). The upper aqueous phase was precipitated with 2propanol. After centrifugation, the resulting RNA pellet was washed with ethanol and resuspended in diethyl pyrocarbonate-treated water. Because of the sensitivity of the PCR, residual contaminating DNA was eliminated by incubation of the sample with RNase-free DNase (Promega). The RNA concentration was determined spectrophotometrically using a Nanodrop instrument (ND-1000; Nanodrop Technologies). The integrity of the RNA was assessed by agarose gel electrophoresis (data not shown). The same procedure was followed for RNA extraction from planktonic cells, which were collected after centrifugation $\left(4500 \mathrm{~g}, 4{ }^{\circ} \mathrm{C}\right.$ ) and immediately resuspended in TRI Reagent (Sigma-Aldrich). Cell pellets were stored at $-20{ }^{\circ} \mathrm{C}$ until they were used for RNA isolation.

Reverse transcription and real-time quantitative PCR. Amplification, detection and analysis of mRNA were performed using the ABI-Prism 7000 sequence detection system (Applied Biosystems) with a SYBR Green PCR master mix (Applied Biosystems). The corresponding oligonucleotide primers were designed using the algorithms provided by Primer Express (Applied Biosystems) for uniformity in size $(\approx 90 \mathrm{bp})$ and melting temperature. For each set of primers, a standard amplification curve was plotted [critical threshold cycle $\left(\mathrm{C}_{\mathrm{t}}\right)$ against log of concentration] and only those with slope of approximately -3 were considered reliable primers. The RT-PCR reaction was performed as described previously (Shemesh et al., 2006); briefly, a RT-PCR reaction mixture $(20 \mu \mathrm{l})$ containing $50 \mathrm{ng}$ random hexamers, $10 \mathrm{mM}$ dNTPs mix and $1 \mu \mathrm{g}$ total RNA was incubated at $65{ }^{\circ} \mathrm{C}$ for 5 min to remove any secondary structure, and placed on ice. Then $10 \times$ RT-PCR buffer, $25 \mathrm{mM}$ $\mathrm{MgCl}_{2}, 0.1 \mathrm{M}$ DTT, $40 \mathrm{U}$ RNaseOUT recombinant RNase inhibitor and $50 \mathrm{U}$ SuperScript II reverse transcriptase (Invitrogen, Life Technologies) were added to each reaction mix. After incubation at $25{ }^{\circ} \mathrm{C}$ for $10 \mathrm{~min}$, the mix was incubated at $42{ }^{\circ} \mathrm{C}$ for $50 \mathrm{~min}$. The reaction was terminated by heating the mixture at $70{ }^{\circ} \mathrm{C}$ for $15 \mathrm{~min}$, and the cDNA samples were stored at $4{ }^{\circ} \mathrm{C}$ until used.

The RT-PCR reaction mixture $(20 \mu \mathrm{l})$ contained $1 \times$ SYBR Green PCR master mix (Applied Biosystems), $1 \mu \mathrm{l}$ cDNA, and $0.5 \mu \mathrm{M}$ of the appropriate forward and reverse PCR primers. PCR conditions included an initial denaturation at $95{ }^{\circ} \mathrm{C}$ for $10 \mathrm{~min}$, followed by a 40 cycle amplification consisting of denaturation at $95{ }^{\circ} \mathrm{C}$ for $15 \mathrm{~s}$, and annealing and extension at $60{ }^{\circ} \mathrm{C}$ for $1 \mathrm{~min}$. All primer pairs were checked for primer-dimer formation by using the dissociation curve analysis. The critical $C_{t}$ was defined as the cycle in which fluorescence becomes detectable above the background fluorescence, and is inversely proportional to the logarithm of the initial number of template molecules. A standard curve was plotted for each primer set with $\mathrm{C}_{\mathrm{t}}$ values obtained from amplification of known quantities of $S$. 
mutans cDNA. The standard curves were used for converting the $\mathrm{C}_{t}$ values into the relative number of cDNA molecules. Contamination by genomic DNA was determined from control reactions devoid of reverse transcriptase. The same procedure was repeated for all the primers.

The expression levels of all the tested genes (Table 1) for real-time RT-PCR were normalized using the $16 \mathrm{~S}$ rRNA gene of $S$. mutans (GenBank accession no. X58303) as an internal standard. There was no significant difference in the expression of the 16S rRNA gene under the various conditions nor in the various samples tested (data not shown). Each assay was performed with at least two independent RNA samples in duplicates.

Statistical analysis. Student's $t$ test was used to calculate the significance of the difference between the mean expression of a given experimental samples and the control samples. The same test was used to analyse the differences in mean biofilm depth between a given experimental samples and the control samples. A $P$ value of $<0.05$ was considered significant.

\section{RESULTS AND DISCUSSION}

\section{Gene expression profile of biofilm versus planktonic environment}

Biofilm formation can be considered as a developmental process, which is characterized through changes of structural and regulatory genes required at the various steps of its formation (O'Toole et al., 2000; Steinberg, 2000). It is clear that micro-organisms undergo alterations during their transition from planktonic organisms to cells that are part of complex, surface-attached community. To gain insight into the similarities and differences in $S$. mutans GS5 gene expression between cells grown in planktonic and biofilm environments, we used comparative real-time RT-PCR analysis. We selected several genes known to be mostly involved in biofilm formation of $S$. mutans and compared their expression under the two conditions. An equal amount of total RNA from each culture phase was used for quantification of the transcript levels of these genes. Because of the sensitivity of real-time PCR and its amenability to the performance of replicates for individual statistical determination, we were able to measure statistically significant changes for the majority of the genes tested. Using the designed primer sets, we differentiated all tested genes by real-time RT-PCR with SYBR Green, and the specificity of the PCR products was confirmed with dissociation curves analysis (data not shown).

In general, all of the genes tested were upregulated in the biofilm compared to cells grown in planktonic conditions (Fig. 1). The greatest induction of gene expression in the biofilm phase was observed for $g t f B$. Biofilm formation was accompanied by a 22 -fold induction in the abundance of mRNA encoding GTFB and 14.8-fold increase in mRNA encoding GTFC. These enzymes synthesize glucan polymers from sucrose, which play a noteworthy role in dental biofilm formation (Kuramitsu, 2001; Steinberg, 2000). Levels of mRNA encoding FTF were induced approximately 11.8-fold in biofilm-derived versus planktonic cells.

vicR-encoding a putative response regulator in the vicRK signal transduction system (Senadheera et al., 2005), was upregulated about twelvefold (Fig. 1). The vicRKX operon is essential for the viability of $S$. mutans. vic gene products appear to modulate adherence, biofilm formation and genetic competence development in S. mutans. The vicRKX operon regulates the expression of several virulenceassociated genes affecting synthesis of polysaccharides, including $g t f B C D, f t f$ and polysaccharide binding sites as $g b p B$ (Senadheera et al., 2005). Moreover, studies conducted utilizing the vicK-deficient mutant in specificpathogen-free rats revealed a significant increase in

Table 1. Nucleotide sequences of primers used in this study

\begin{tabular}{|c|c|c|c|}
\hline \multirow[t]{2}{*}{ Gene $^{\star}$} & \multirow[t]{2}{*}{ Description } & \multicolumn{2}{|c|}{ Primer sequence $\left(5^{\prime}-3^{\prime}\right)$} \\
\hline & & Forward & Reverse \\
\hline $\mathrm{ftf}$ & FTF, fructan production & AAATATGAAGGCGGCTACAACG & CTTCACCAGTCTTAGCATCCTGAA \\
\hline$g t f B$ & GTFB, glucan production & AGCAATGCAGCCAATCTACAAAT & ACGAACTTTGCCGTTATTGTCA \\
\hline gtfC & GTFC, glucan production & GGTTTAACGTCAAAATTAGCTGTATTAGC & CTCAACCAACCGCCACTGTT \\
\hline $16 S r R N A$ & Normalizing internal standard & CCTACGGGAGGCAGCAGTAG & CAACAGAGCTTTACGATCCGAAA \\
\hline $\operatorname{brpA}$ & Biofilm-regulation protein & GGAGGAGCTGCATCAGGATTC & AACTCCAGCACATCCAGCAAG \\
\hline $\operatorname{comDE}$ & Competence-stimulating peptide & ACAATTCCTTGAGTTCCATCCAAG & TGGTCTGCTGCCTGTTGC \\
\hline $\operatorname{vicR}$ & Two-component regulatory system & TGACACGATTACAGCCTTTGATG & $\begin{array}{l}\text { CGTCTAGTTCTGGTAACATTAAGT- } \\
\text { CCAATA }\end{array}$ \\
\hline$g b p B$ & GBP & ATGGCGGTTATGGACACGTT & TTTGGCCACCTTGAACACCT \\
\hline spaP & Cell surface antigen, SpaP & GACTTTGGTAATGGTTATGCATCAA & TTTGTATCAGCCGGATCAAGTG \\
\hline relA & $\begin{array}{l}\text { Guanosine tetra (penta)-phosphate } \\
\text { synthetase }\end{array}$ & ACAAAAAGGGTATCGTCCGTACAT & AATCACGCTTGGTATTGCTAATTG \\
\hline smu0630 & $\begin{array}{l}\text { Biofilm-formation hypothetical } \\
\text { protein }\end{array}$ & GTTAGTTCTGGTTTTGACCGCAAT & CССТСAACAACAACATCAAAGGT \\
\hline
\end{tabular}

${ }^{\star}$ Based on the NCBI S. mutans genome database. 


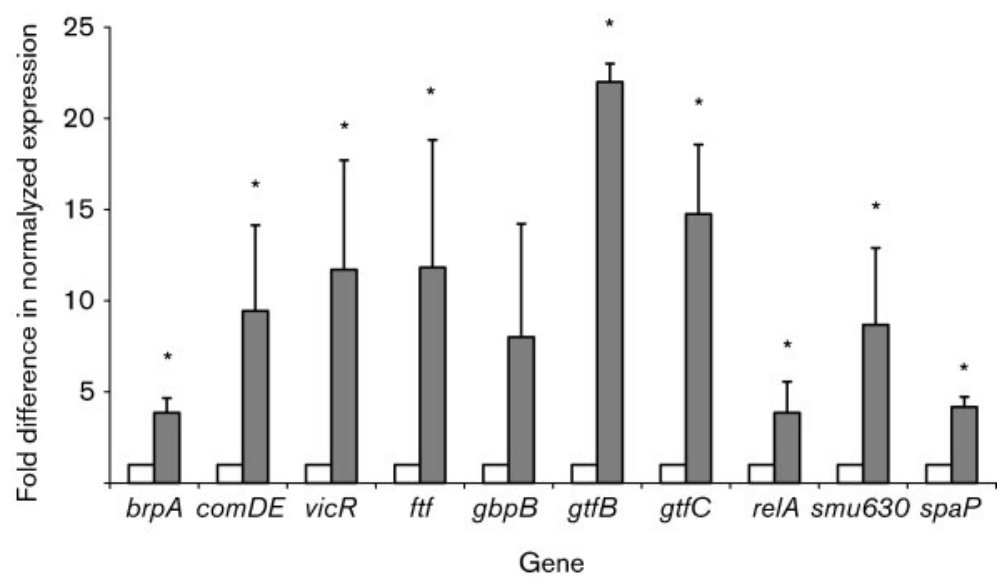

Fig. 1. mRNA abundance of $S$. mutans GS5 grown in BHI broth in biofilm (grey bars) versus planktonic environment (white bars). The data are expressed as the means and SDS of three biologically independent experiments performed in duplicates. ${ }^{*}$, Statistically significant differences $(P<0.05)$ between gene expression in biofilm relative to planktonic environment.

smooth-surface plaque compared with the wild-type UA159 parent, whereas the incidence of dental caries was not affected (Senadheera et al., 2005). The ability of $S$. mutans to colonize teeth is paramount to the initiation and progression of dental caries. Among the S. mutans surfaceassociated proteins that facilitate adherence and colonization are GTFs and a FTF, which catalyse the cleavage of sucrose to synthesize extracellular glucan and fructan polysaccharides, respectively (Hanada \& Kuramitsu, 1988). GTFB and GTFC produce water-insoluble glucans, which function as adhesive molecules that anchor bacteria to the tooth pellicle (Nakano \& Kuramitsu, 1992). Oral bacterial aggregation is also mediated by interactions between surface-associated GBPs that adhere to glucans, thereby promoting plaque formation (Steinberg, 2000). Collectively, these enzymes serve an important role in the pathogenicity of $S$. mutans and are regulated by the vicRK signalling pathway. For instance, rats infected with $S$. mutans gtf $B C D$ - or $f t f$-deficient mutants had significantly reduced levels of dental caries (Burne et al., 1996; Munro et al., 1991).

\section{Transcription of biofilm-associated genes is growth media dependent}

The nutrient content of the medium was found to regulate the development of biofilms in several organisms (Carlson, 2000; Gilmore et al., 2003). Therefore, we tested some nutrient components for their influence on gene expression in S. mutans biofilms under various conditions. Several media and carbon sources were examined in order to evaluate the gene expression profiles of biofilm on polystyrene surfaces. We initially assessed $S$. mutans GS5 biofilm formation in TY growth medium supplemented with 10 or $40 \mathrm{~g}$ sucrose $\mathrm{l}^{-1}$. According to CLSM images (see Supplementary Fig. S1a, b, c, d, e, f, g, h, i available with the online journal), relatively little growth and biofilm formation were observed in TY growth medium without a carbon source (Supplementary Fig. S1a available with the online journal). The addition of sucrose to the TY growth medium resulted in a significant increase of adherentpopulation cells compared to unsupplemented TY medium, with up to 380-micron depths of biofilm (Supplementary Fig. S1b, c available with the online

Table 2. Biofilm depth analysis by CSLM

\begin{tabular}{|lc|}
\hline Biofilm growth medium & Mean biofilm depth $(\boldsymbol{\mu m})^{\star}$ \\
\hline Unsupplemented TY & $138 \pm 28$ \\
TY supplemented with $10 \mathrm{~g}$ sucrose $\mathrm{l}^{-1}$ & $250 \pm 72 \dagger$ \\
TY supplemented with $40 \mathrm{~g}$ sucrose $1^{-1}$ & $293 \pm 130 \dagger$ \\
TY supplemented with $2 \mathrm{~g}$ glucose $1^{-1}$ & $138 \pm 72$ \\
TY supplemented with $10 \mathrm{~g}$ sucrose $1^{-1}$ and $2 \mathrm{~g}$ glucose $1^{-1}$ & $238 \pm 47 \dagger$ \\
TY supplemented with $40 \mathrm{~g}$ sucrose $1^{-1}$ and $2 \mathrm{~g}$ glucose $1^{-1}$ & $199 \pm 67$ \\
Unsupplemented BHI & $92 \pm 13$ \\
BHI supplemented with $10 \mathrm{~g}$ sucrose $1^{-1}$ & $63 \pm 17 \ddagger$ \\
BHI supplemented with $40 \mathrm{~g}$ sucrose $1^{-1}$ & $94 \pm 29$ \\
\hline
\end{tabular}

${ }^{*}$ Data show means \pm SD of generated biofilm depth from three independent experiments.

$\dagger$ Statistically significant differences $(P<0.05)$ between mean biofilm depths in given sample versus unsupplemented TY medium.

\#Statistically significant differences $(P<0.05)$ between mean biofilm depth in given sample versus unsupplemented BHI medium. 


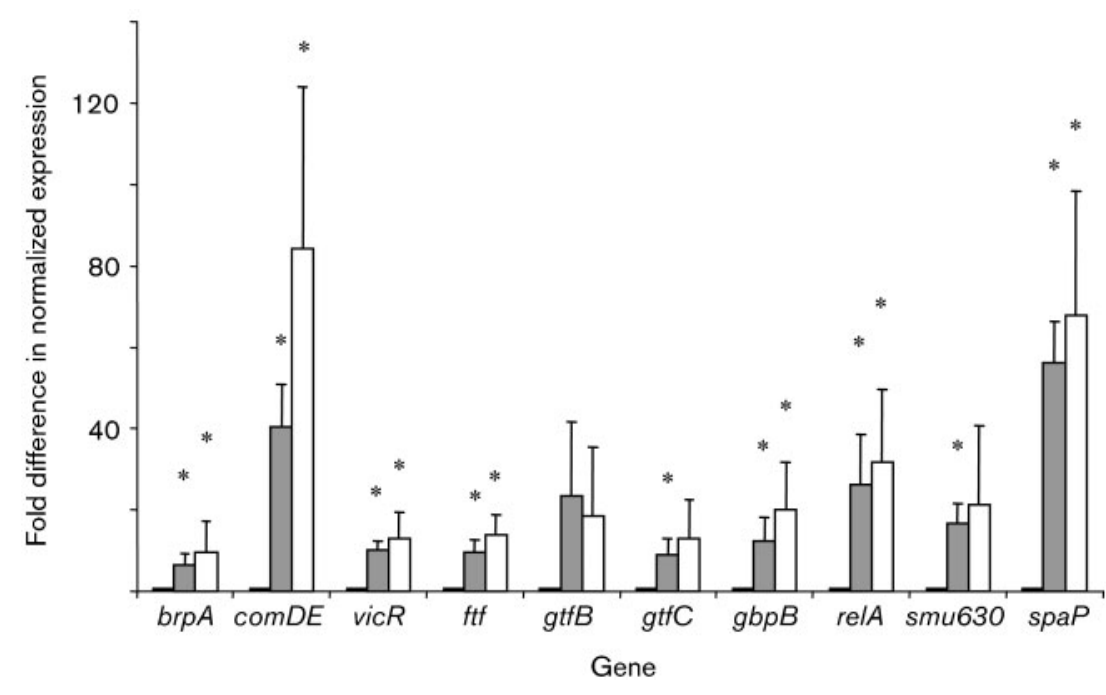

Fig. 2. Sucrose effect on gene expression of S. mutans biofilms formed on polystyrene surfaces in TY medium. The data are expressed as the means and SDS of three biological experiments performed in duplicates. *, Statistically significant differences $(P<0.05)$ between gene expression in the presence of sucrose-supplemented TY and unsupplemented TY medium. Black bars, unsupplemented TY; grey bars, TY+10 g sucrose $\mathrm{I}^{-1}$; white bars, $\mathrm{TY}+40 \mathrm{~g}$ sucrose $\mathrm{I}^{-1}$.

journal). But the addition of glucose in TY growth medium supplemented with sucrose caused a dramatic reduction in the depth of biofilm formed (Supplementary Fig. S1e, $\mathrm{f}$ available with the online journal). Moreover, the biofilm depth in BHI medium supplemented with sucrose was notably decreased compared to TY medium supplemented with sucrose (Table 2).

Since the role of sucrose in $S$. mutans biofilm formation has been well documented (Burne et al., 1997; Hudson \& Curtiss, 1990; Kuramitsu, 1993), we focused our investigation on sucrose-influenced gene expression in this organism. The real-time RT-PCR results presented in Fig. 2 show that all tested genes were significantly upregulated in TY growth medium supplemented with 10 or $40 \mathrm{~g}$ sucrose $1^{-1}$, in comparison to unsupplemented TY medium. The greatest relative increase was observed for comDE, with mRNA levels increased 84.3-fold with $40 \mathrm{~g}$ sucrose $1^{-1}$ in TY medium. The comDE encodes a twocomponent signal transduction system, and together with the competence-stimulating peptide (encoded by $\operatorname{com} C$ ) regulates genetic transformation and biofilm formation in
S. mutans (Li et al., 2002). spaP was also found to be expressed at a significantly increased level in the presence of sucrose. Levels of spaP mRNA were increased approximately 68 -fold with $40 \mathrm{~g}$ sucrose $\mathrm{l}^{-1}$ and 56 -fold with $10 \mathrm{~g}$ sucrose $1^{-1}$. Recently, it has been shown that a $S$. mutans GS5 strain has low cariogenic properties, apparently due to the loss of the SpaP (PAc) protein from the cell wall (Sato et al., 2002). This effect was related to premature termination occurring at codon 1159 of the spaP by frameshift mutation. Similarly, a point mutation in the $g b p C$ gene of this strain may be another factor contributing to the low cariogenicity of GS5 strain, since GPB, as well as SpaP, plays important role in adhesion process of $S$. mutans (Murakami et al., 1997; Sato et al., 2002).

In contrast to TY growth medium, the addition of sucrose to BHI medium downregulated the expression of most tested genes. brpA $(l y t R)$ and $c o m D E$ were the genes most significantly decreased (about eightfold and fivefold, respectively) in the presence of $40 \mathrm{~g}$ sucrose $1^{-1}$ in BHI medium (Fig. 3). Interestingly, comparison of gene expression between BHI and TY media with no added

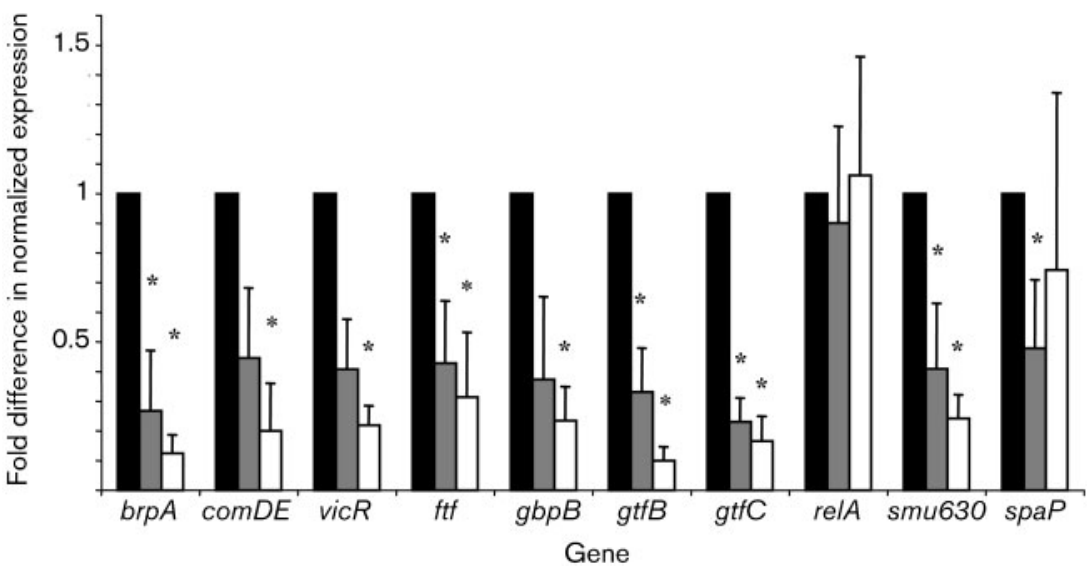

Fig. 3. Sucrose effect on gene expression of S. mutans biofilms formed on polystyrene surfaces in BHI medium. The results represent the means and SDS of at least two independent experiments performed in duplicates. *, Statistically significant differences $(P<0.05)$ between gene expression in the presence of sucrose-supplemented $\mathrm{BHI}$ and unsupplemented $\mathrm{BHI}$ media. Black bars, unsupplemented $\mathrm{BHI}$; grey bars, $\mathrm{BHI}+10 \mathrm{~g}$ sucrose $\mathrm{I}^{-1}$; white bars, $\mathrm{BHI}+40 \mathrm{~g}$ sucrose $\mathrm{I}^{-1}$. 


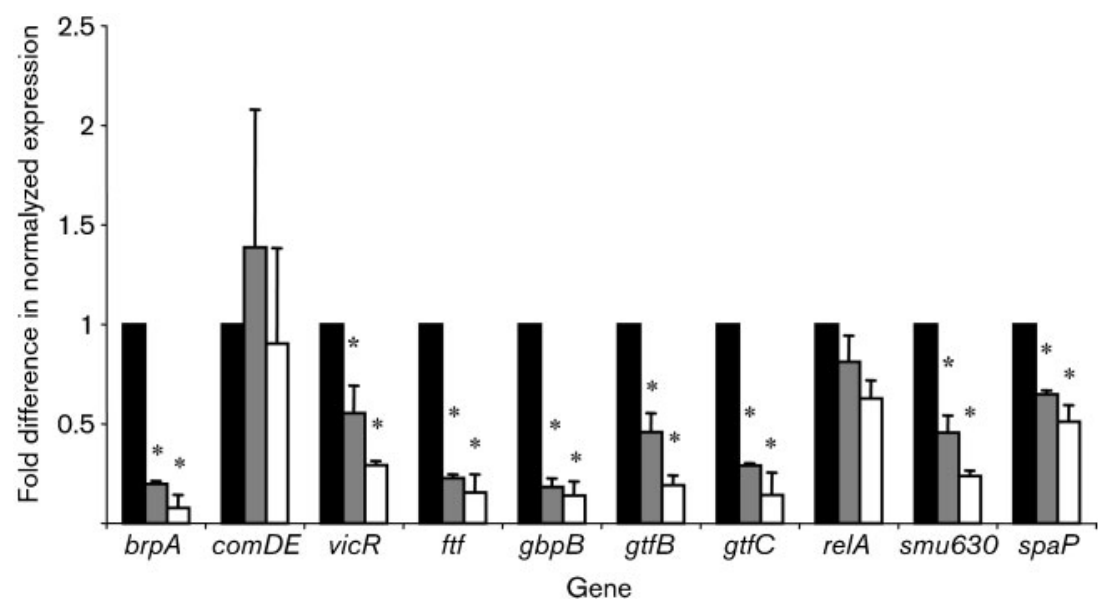

Fig. 4. Sucrose effect on gene expression of S. mutans biofilms formed on polystyrene surfaces in TY medium supplemented with glucose. The data are expressed as the means and SDS of three independent experiments performed in duplicates. *, Statistically significant differences $(P<0.05)$ between gene expression in the presence of sucrose and glucose supplemented TY medium and glucose-supplemented TY medium. Black bars,

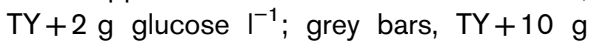
sucrose $\mathrm{I}^{-1}+2 \mathrm{~g}$ glucose $\mathrm{I}^{-1}$; white bars,

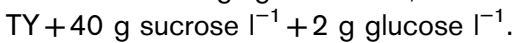

carbohydrate, demonstrated upregulation of most tested genes in BHI medium (data not shown). In order to understand the differences of this sucrose effect on genes, we compared the carbohydrate contents of these two media. The presence of glucose in BHI medium was the major distinction between them, and therefore we examined the effect of sucrose in TY growth medium in the presence of glucose. The addition of sucrose to TY medium supplemented with glucose significantly downregulated the expression of most genes tested. The greatest reduction, of approximately 12 -fold, was observed for $\operatorname{brp} A$ (Fig. 4), which is consistent with an effect of sucrose in BHI medium (Fig. 3). Recently, it has been shown that the putative autolysin regulator LytR in S. mutans plays a role in cell division and has an important role in sucroseindependent attachment to polystyrene surfaces (Wen \& Burne, 2002; Yoshida \& Kuramitsu, 2002; Chatfield et al., 2005). We suggest, therefore, that the biosynthesis of LytR, in the presence of $40 \mathrm{~g}$ sucrose $1^{-1}$ supplemented with glucose, becomes non-essential for the bacterial adhesion and biofilm development.

The expression of $g b p$, which encodes a GBP in S. mutans, was also downregulated sevenfold by the addition of $40 \mathrm{~g}$ sucrose $1^{-1}$ to TY medium supplemented with glucose (Fig. $4)$. This reduction in expression was accompanied by an approximately sevenfold reduction in the abundance of mRNAs encoding FTF and GTFC. Levels of mRNA encoding FTF were found to be reduced about 4.5 -fold in TY medium supplemented with glucose and $10 \mathrm{~g}$ sucrose $1^{-1}$. Noticeably, the inclusion of glucose in the presence of sucrose resulted in an abrogation of the sucrose induction of gene expression in all cases except comDE, although this is different to what was observed when BHI medium was supplemented with sucrose (Fig. 3).

It is of interest that the effect of sucrose on S. mutans GS5 biofilm genes expression in TY medium supplemented with glucose and BHI media was similar. Other studies on S. mutans MT8148, using real-time RT-PCR, have shown decreased expression of $g t f B$ and $g t f C$ in the presence of
20 g sucrose $1^{-1}$ (Fujiwara et al., 2002). A plasmid-based reporter system using a luciferase assay has revealed that expression of the upstream regions of $g t f B / C$ remained constant in the presence of sucrose, glucose and fructose (Goodman \& Gao, 2000). On the other hand, recent realtime RT-PCR experiments indicated that wapA gene expression was strongly repressed by sucrose in both planktonic and biofilm cells (Zhu et al., 2006). Other studies showed that sucrose induced the expression of $\mathrm{ftf}$ CAT and $g t f B / C$-CAT in S. mutans (Li \& Burne, 2001; Burne et al., 1997). These conflicting results from the literature indicate that the expression of those genes is dependent on several factors, such as bacterial strain, growth phase and mode, and other environmental parameters, such as growth media and carbohydrate. Clearly, further investigations are required for understanding the exact mechanism involved in the regulation of biofilmassociated gene expression by the various strains of $S$. mutans streptococci as one means to prevent biofilm formation.

There are an abundance of carbohydrates produced by oral bacteria, and a wide variety of dietary carbohydrates in the oral cavity. Out of the tested carbohydrates, glucose was found to have the most effect on S. mutans GS5 biofilm gene expression. It is of interest that biofilm-associated gene expression was significantly upregulated in TY growth medium supplemented with sucrose, whereas the inclusion of glucose (in the presence of sucrose) abrogated this effect for most of the tested genes. It is conceivable that the presence of glucose counteracts the effect of sucrose in this system, as the micro-organisms prefer more simple sugars as the major carbon source. The biofilm developmental process is characterized by the balance between free and attached cells at various steps of its formation. Since the simple sugar is present in the environment, the bacterial cells might prefer to stay as plankton and to downregulate the sucrose-dependent cell-cell adhesion and expression of biofilm formation genes. Good evidence of this phenomenon is direct comparison of the optical images by CLSM 
(Table 2, Supplementary Fig. S1 available with the online journal), demonstrating that addition of glucose, in the presence of sucrose, is accompanied by a reduction in biofilm thickness.

In conclusion, this report describes the modulation of $S$. mutans gene expression in biofilm versus planktonic environment. Differential analysis of the transcripts from $S$. mutans grown in media of various nutrient content revealed significant alterations in the expression of the genes involved in biofilm formation. The results presented here provide new insights at the molecular level of gene expression in this bacterium grown under biofilm conditions, facilitating a better understanding of the mechanism of biofilm formation by $S$. mutans.

\section{ACKNOWLEDGEMENTS}

This work is part of the $\mathrm{PhD}$ dissertation of M.S.

\section{REFERENCES}

Banas, J. A. \& Vickerman, M. M. (2003). Glucan-binding proteins of the oral streptococci. Crit Rev Oral Biol Med 14, 89-99.

Bowden, G. H. \& Hamilton, I. R. (1998). Survival of oral bacteria. Crit Rev Oral Biol Med 9, 54-85.

Brown, T. A., Jr, Ahn, S. J., Frank, R. N., Chen, Y. Y., Lemos, J. A. \& Burne, R. A. (2005). A hypothetical protein of Streptococcus mutans is critical for biofilm formation. Infect Immun 73, 3147-3151.

Burne, R. A., Chen, Y. Y., Wexler, D. L., Kuramitsu, H. \& Bowen, W. H. (1996). Cariogenicity of Streptococcus mutans strains with defects in fructan metabolism assessed in a program-fed specific-pathogen-free rat model. J Dent Res 75, 1572-1577.

Burne, R. A., Chen, Y. Y. \& Penders, J. E. (1997). Analysis of gene expression in Streptococcus mutans in biofilms in vitro. Adv Dent Res 11, 100-109.

Carlson, J. (2000). Growth and nutrition as ecological factors. In Oral Bacterial Ecology: the Molecular Basis, pp. 67-130. Edited by H. K. Kuramitsu \& R. P. Ellen. Wymondham: Horizon Scientific Press.

Chatfield, C. H., Koo, H. \& Quivey, R. G., Jr (2005). The putative autolysin regulator LytR in Streptococcus mutans plays a role in cell division and is growth-phase regulated. Microbiology 151, 625-631.

Costerton, J. W., Cheng, K. J., Geesey, G. G., Ladd, T. I., Nickel, J. C., Dasgupta, M. \& Marrie, T. J. (1987). Bacterial biofilms in nature and disease. Annu Rev Microbiol 41, 435-464.

Fujiwara, T., Hoshino, T., Ooshima, T. \& Hamada, S. (2002). Differential and quantitative analyses of mRNA expression of glucosyltransferases from Streptococcus mutans MT8148. J Dent Res 81, 109-113.

Gilmore, K. S., Srinivas, P., Akins, D. R., Hatter, K. L. \& Gilmore, M. S. (2003). Growth, development, and gene expression in a persistent Streptococcus gordonii biofilm. Infect Immun 71, 4759-4766.

Goodman, S. D. \& Gao, Q. (2000). Characterization of the $g t f B$ and gtfC promoters from Streptococcus mutans GS-5. Plasmid 43, 85-98.

Hall-Stoodley, L., Costerton, J. W. \& Stoodley, P. (2004). Bacterial biofilms: from the natural environment to infectious diseases. Nat Rev Microbiol 2, 95-108.
Hanada, N. \& Kuramitsu, H. K. (1988). Isolation and characterization of the Streptococcus mutans gtfC gene, coding for synthesis of both soluble and insoluble glucans. Infect Immun 56, 1999-2005.

Hudson, M. C. \& Curtiss, R., III (1990). Regulation of expression of Streptococcus mutans genes important to virulence. Infect Immun 58, 464-470.

Jakubovics, N. S., Stromberg, N., van Dolleweerd, C. J., Kelly, C. G. \& Jenkinson, H. F. (2005). Differential binding specificities of oral streptococcal antigen I/II family adhesins for human or bacterial ligands. Mol Microbiol 55, 1591-1605.

Kiska, D. L. \& Macrina, F. L. (1994). Genetic regulation of fructosyltransferase in Streptococcus mutans. Infect Immun 62, 1241-1251.

Kuramitsu, H. K. (1993). Virulence factors of mutans streptococci: role of molecular genetics. Crit Rev Oral Biol Med 4, 159-176.

Kuramitsu, H. K. (2001). Virulence properties of oral bacteria: impact of molecular biology. Curr Issues Mol Biol 3, 35-36.

Lee, S. F., Progulske-Fox, A., Erdos, G. W., Piacentini, D. A., Ayakawa, G. Y., Crowley, P. J. \& Bleiweis, A. S. (1989). Construction and characterization of isogenic mutants of Streptococcus mutans deficient in major surface protein antigen P1 (I/II). Infect Immun 57, 3306-3313.

Lee, S. F., Delaney, G. D. \& Elkhateeb, M. (2004). A two-component $\operatorname{cov} R S$ regulatory system regulates expression of fructosyltransferase and a novel extracellular carbohydrate in Streptococcus mutans. Infect Immun 72, 3968-3973.

Lemos, J. A. \& Burne, R. A. (2002). Regulation and physiological significance of ClpC and ClpP in Streptococcus mutans. J Bacteriol 184, 6357-6366.

Lemos, J. A., Brown, T. A., Jr \& Burne, R. A. (2004). Effects of RelA on key virulence properties of planktonic and biofilm populations of Streptococcus mutans. Infect Immun 72, 1431-1440.

Li, Y. \& Burne, R. A. (2001). Regulation of the $\mathrm{gtfBC}$ and $\mathrm{ftf}$ genes of Streptococcus mutans in biofilms in response to $\mathrm{pH}$ and carbohydrate. Microbiology 147, 2841-2848.

Li, Y. H., Tang, N., Aspiras, M. B., Lau, P. C., Lee, J. H., Ellen, R. P. \& Cvitkovitch, D. G. (2002). A quorum-sensing signaling system essential for genetic competence in Streptococcus mutans is involved in biofilm formation. J Bacteriol 184, 2699-2708.

Marsh, P. D. (2005). Dental plaque: biological significance of a biofilm and community life-style. J Clin Periodontol 32 (Suppl. 6), $7-15$.

Munro, C., Michalek, S. M. \& Macrina, F. L. (1991). Cariogenicity of Streptococcus mutans V403 glucosyltransferase and fructosyltransferase mutants constructed by allelic exchange. Infect Immun 59, 23162323.

Murakami, Y., Nakano, Y., Yamashita, Y. \& Koga, T. (1997). Identification of a frameshift mutation resulting in premature termination and loss of cell wall anchoring of the PAc antigen of Streptococcus mutans GS-5. Infect Immun 65, 794-797.

Nakano, Y. J. \& Kuramitsu, H. K. (1992). Mechanism of Streptococcus mutans glucosyltransferases: hybrid-enzyme analysis. J Bacteriol 174, 5639-5646.

O'Toole, G., Kaplan, H. B. \& Kolter, R. (2000). Biofilm formation as microbial development. Annu Rev Microbiol 54, 49-79.

Sato, Y., Okamoto, K. \& Kizaki, H. (2002). gbpC and $p a c$ gene mutations detected in Streptococcus mutans strain GS-5. Oral Microbiol Immunol 17, 263-266.

Senadheera, M. D., Guggenheim, B., Spatafora, G. A., Huang, Y. C., Choi, J., Hung, D. C., Treglown, J. S., Goodman, S. D., Ellen, R. P. \& Cvitkovitch, D. G. (2005). A VicRK signal transduction system in 
Streptococcus mutans affects $g t f B C D, g b p B$, and $f t f$ expression, biofilm formation, and genetic competence development. J Bacteriol 187, 4064-4076.

Shemesh, M. \& Steinberg, D. (2006). In vitro binding interactions of oral bacteria with immobilized fructosyltransferase. J Appl Microbiol 100, 871-877.

Shemesh, M., Tam, A., Feldman, M. \& Steinberg, D. (2006). Differential expression profiles of Streptococcus mutans $\mathrm{ftf}$, gtf and vicR genes in the presence of dietary carbohydrates at early and late exponential growth phases. Carbohydr Res 341, 2090-2097.

Shemesh, M., Tam, A. \& Steinberg, D. (2007). Differential gene expression profiling of Streptococcus mutans cultured under biofilm and planktonic conditions. Microbiology 153, 1307-1317.

Steinberg, D. (2000). Studying plaque biofilms on various dental surfaces. In Handbook of Bacterial Adhesion: Principles, Methods, and Applications, pp. 353-370. Edited by Y. H. An \& R. J. Friedman. Totowa, NJ: Humana Press.
Tam, A., Shemesh, M., Wormser, U., Sintov, A. \& Steinberg, D. (2006). Effect of different iodine formulations on the expression and activity of Streptococcus mutans glucosyltransferase and fructosyltransferase in biofilm and planktonic environments. J Antimicrob Chemother 57, 865-871.

Wen, Z. T. \& Burne, R. A. (2002). Functional genomics approach to identifying genes required for biofilm development by Streptococcus mutans. Appl Environ Microbiol 68, 1196-1203.

Whiteley, M., Bangera, M. G., Bumgarner, R. E., Parsek, M. R., Teitzel, G. M., Lory, S. \& Greenberg, E. P. (2001). Gene expression in Pseudomonas aeruginosa biofilms. Nature 413, 860-864.

Yoshida, A. \& Kuramitsu, H. K. (2002). Multiple Streptococcus mutans genes are involved in biofilm formation. Appl Environ Microbiol 68, 6283-6291.

Zhu, L., Kreth, J., Cross, S. E., Gimzewski, J. K., Shi, W. \& Qi, F. (2006). Functional characterization of cell-wall-associated protein WapA in Streptococcus mutans. Microbiology 152, 2395-2404. 